tenderness, disappeared within 12-24 hours. The increased white blood cell count returned to normal within 24-48 hours. 5 patients had endoscopic stent extraction 2 weeks later, while one had stent migration and extrusion spontaneously. Normal morphology of the appendix opening was observed in all patients at the review. And there were no recurrences during 9-18 months of follow-up.

Conclusions Endoscopic retrograde appendix stenting is feasible, safe and effective. With less trauma and quick recovery, it is a treatment of appendicitis that particularly suited to the oldest-old patients.

\section{IDDF2019-ABS-0152 A SINGLE-CENTER PHASE II STUDY OF APATINIB COMBINED WITH S1 AS A MAINTENANCE TREATMENT IN METASTATIC GASTRIC CANCER PATIENTS}

${ }^{1}$ Yunqi Hua*, ${ }^{2}$ Fangrui Yin, ${ }^{1}$ Xinyi Zhang, ' ${ }^{1}$ ongyan Yang, ${ }^{1}$ Yunjian Jin, ${ }^{1}$ Chenlin Wang, ${ }^{1} X i$ Li. 'Cancer Biotherapy Center and Oncology Department, Baotou Tumor Hospital, Clinical Oncology of Baotou Medical College, China; '2Department of Central Laboratory, The First Affiliated Hospital of Baotou Medical College, China

\subsection{6/gutjint-2019-IDDFabstracts. 168}

Background Antiangiogenesis therapy plays an important role in cancer treatment. Apatinib mesylate, a small molecule tyrosine kinase inhibitor targeting vascular endothelial growth factor receptor-2(VEGFR-2), has been recommended as a third-line treatment for metastatic gastric cancer patients. This study was conducted to assess the efficacy and safety of apatinib combined with S1 as a maintenance treatment in metastatic gastric cancer patients.

Methods This single-center, open-label, single arm study enrolled patients with metastatic gastric cancer patients, pretreated chemotherapy with S1 regimens and their efficacy of chemotherapy was stable. The primary end point of this study was progression-free survival (PFS). Secondary end points included objective response rate (ORR), disease control rate (DCR), and toxicity. Apatinib was administered as $500 \mathrm{mg}$ daily on days 1 through 28 of each 4-week cycle, and S1 35$40 \mathrm{mg} / \mathrm{m}^{2}$ take orally twice a day on 1 through 14 of each $3-$ week cycle.

Results So far, the study is continuing, and 15 patients were enrolled with a median age of 52 years (range, 33 to 62 years) and received apatinib with S1 for a median of 4 cycles (range from 0 to 10 cycles). 11 (73.3\%) patients experienced dose reduction during treatment. Median PFS of all 15 patients was 8.6 months (95\% confidence interval (CI), $4.5 \mathrm{~m}$ - $13.7 \mathrm{~m}) .12$ patients were eligible for efficacy analysis. ORR was $33.3 \%$ (4/12). DCR was $66.7 \%$ (8/12). The most common grade $3 / 4$ treatment-related AEs were hypertension $25.0 \%(3 / 12)$, hand-foot syndrome $8.3 \%(1 / 12)$, and proteinuria $8.3 \%(1 / 12)$. Of two possibly drug-related SAEs recorded in the study, 1 death occurred within 28 days of last treatment and was considered to be the result of disease progression.

Conclusions Apatinib combined with $\mathrm{S} 1$ as a maintenance treatment can prolong PFS in patients with metastatic gastric cancer, and the toxicity is manageable. Apatinib combined with S1 exhibited objective efficacy and it might be better to be tested in metastatic gastric cancer. The maintenance therapy of metastatic gastric cancer is worthy of clinical randomized controlled study.

\section{IDDF2019-ABS-0154 UPPER GASTROINTESTINAL TRACT INVOLVEMENT IN CROHN'S DISEASE IN CHINA: FREQUENCY, ENDOSCOPIC FEATURES, RELATED FACTORS, AND PROGNOSIS}

Yubei Gu*, Zhong Jie. Rui Jin Hospital, Affiliated to Shanghai Jiao Tong University, School of Medicine, China

\subsection{6/gutjnl-2019-IDDFabstracts. 169}

Background The clinical studies in the field of UGI-CD are scarce in China. A retrospective cohort study was performed to analyze the clinical characteristics of UGI-CD.
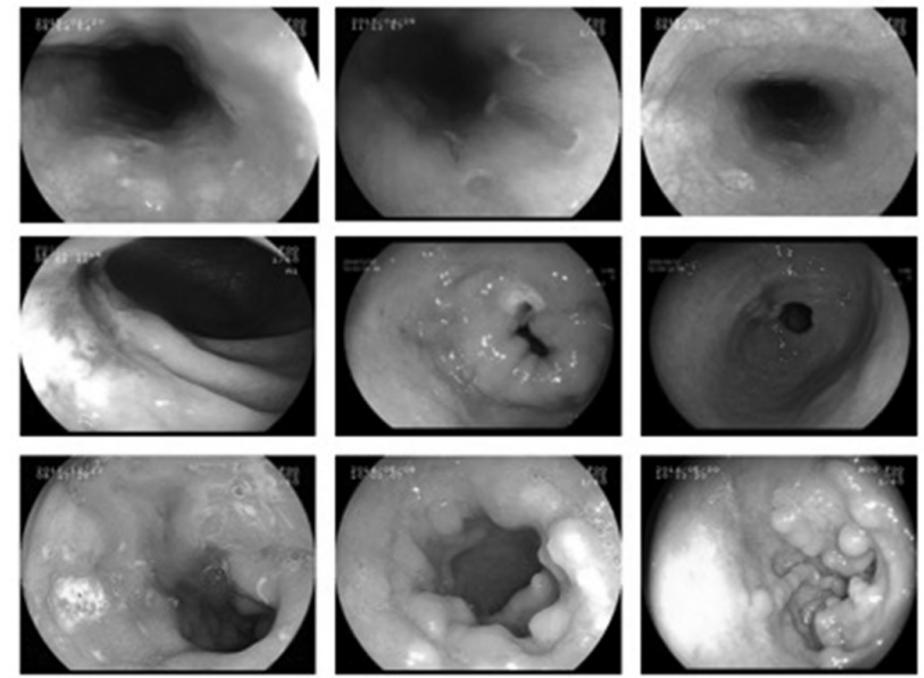
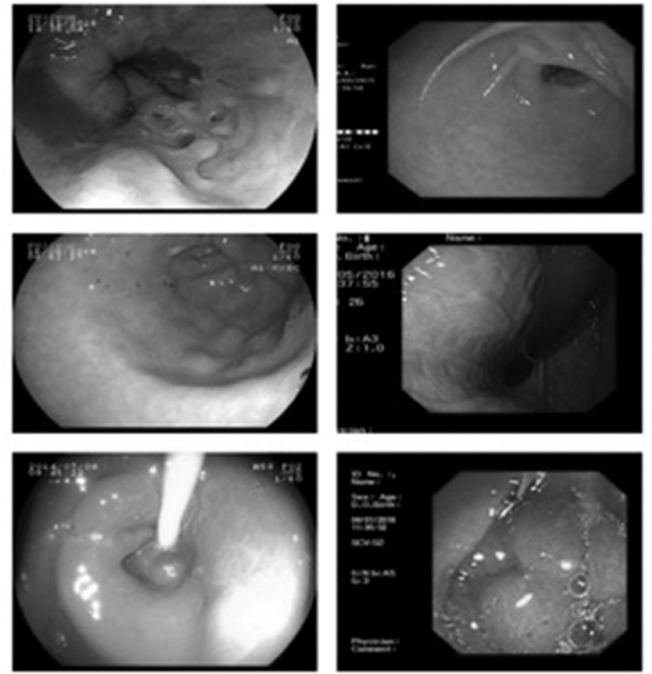

Abstract IDDF2019-ABS-0154 Figure 1 Endoscopic features of UGI-CD 
Methods Patients at Shanghai Ruijin Hospital from 2014 to 2016 were consecutively enrolled. They were divided into UGI+ group and UGI- group based on endoscopy and pathology results. Features of UGI-CD were analyzed and the prognosis was followed-up.

\begin{tabular}{llllll}
\multicolumn{6}{l}{ Abstract IDDF2019-ABS-0154 Table 1} \\
\hline & Ulcer & $\begin{array}{l}\text { Protruding } \\
\text { lesions }\end{array}$ & $\begin{array}{l}\text { Bamboo joint-like } \\
\text { appearance }\end{array}$ & Stenosis & Fistula \\
\hline $\begin{array}{l}\text { Esophagus } \\
\text { Gastric fundus }\end{array}$ & 4 & & $14(20.6 \%)$ & 1 \\
Gastric body & 1 & 1 & & & \\
$\begin{array}{l}\text { Stomach Angle } \\
\text { Gastric antrum }\end{array}$ & 1 & 6 & & 2 & 1 \\
$\begin{array}{l}\text { Pylorus } \\
\text { Duodenal bulb }\end{array}$ & 12 & $10(14.7 \%)$ & & \\
$\begin{array}{l}\text { Duodenal } \\
\text { descendent }\end{array}$ & 4 & & & & \\
Total & 31 & $17(25 \%)$ & $14(20.6 \%)$ & $4(5.8 \%)$ & $2(2.9 \%)$ \\
& $(45.6 \%)$ & & & & \\
\hline
\end{tabular}

Results 76 subjects were enrolled in this study. (1) 46 cases $(60.5 \%)$ had 68 positive endoscopic manifestations. Endoscopic features were diverse and the bamboo joint-like appearance of the gastric fundus had the highest incidence, followed by duodenal ulcers and bamboo joint-like appearance of the duodenal bulb (table 1 and figure 1). According to the UGI-SESCD, patients with a score of 5 and above accounted for only $23.9 \%$.

(2) Male sex and presence of ileocolon lesions were independent risk factors for UGI-CD $(\mathrm{p}<0.05)$.

(3) No significant difference between the UGI+ group and the UGI- group in the 3-year no surgery and the 3-year no complication rates $(\mathrm{p}>0.05)$. Further subgroup analysis showed that the 3-year event-free survival rate in the UGI+DB+ group $(68.0 \%)$ was significantly lower than that in the UGI$(88.9 \%)$ and UGI+DB- (87.9\%)groups ( $p=0.015)$.

Conclusions Upper gastrointestinal tract involvement in newly diagnosed CD patients is not rare. UGI+ patients with duodenal bulb involvement had significantly higher rates of surgery or complications. Therefore, active treatment should be promptly provided to this subgroup of patients to improve their prognosis.

\section{IDDF2019-ABS-0155 THE CLINICAL FEATURES AND PROGNOSTIC FACTORS OF PRIMARY GASTROINTESTINAL DIFFUSE LARGE B- CELL LYMPHOMA: A SINGLE CENTER STUDY OF 312 PATIENTS}

Yubei Gu*, Qiangqiang Wu, Pengpeng Xu, Jie Zhong. Rui Jin Hospital, Affiliated to Shanghai Jiao Tong University, School of Medicine, China

\subsection{6/gutjnl-2019-IDDFabstracts.170}

Background To investigate the clinical features and prognostic factors of patients with primary gastrointestinal diffuse large B-cell lymphoma (PGI-DLBCL).

Methods De novo PGI-DLBCL patients treated in Shanghai Ruijin hospital from January 2000 to January 2017 were enrolled. Clinical data, endoscopic profiles, imaging, pathological features were retrospectively analyzed.

Results 312 PGI-DLBCL patients were included. The median age of onset was 59 years. (1)Clinical manifestations: abdominal pain $(58.7 \%)$ and B symptoms (34.3\%) were the most common clinical manifestations. Other manifestations included gastrointestinal bleeding, intestinal obstruction, abdominal mass and perforation. (2)The involved areas: The most involved areas were the stomach, 58.3\%, colon, $28.2 \%$, duodenal and small intestine, $20.2 \%$ and esophagus (0.6\%), among which 23 cases $(7.4 \%)$ presented multiple

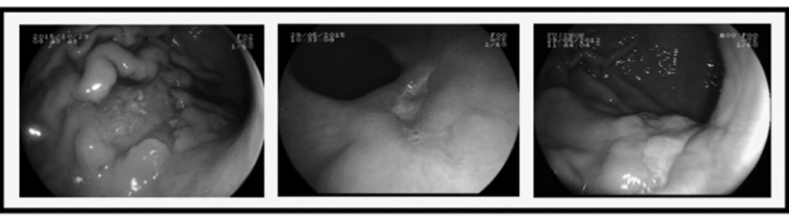

Ulcer type

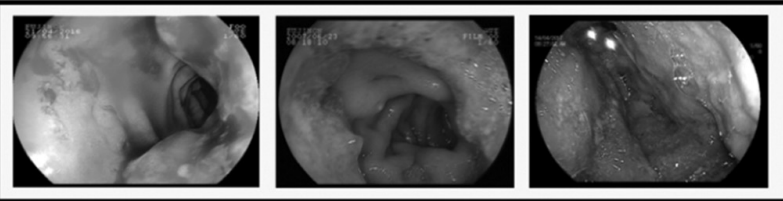

Diffuse infiltration

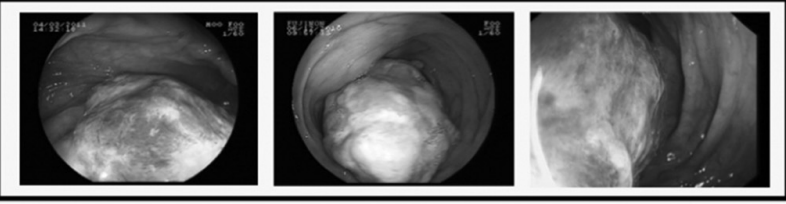

Protruded lesion

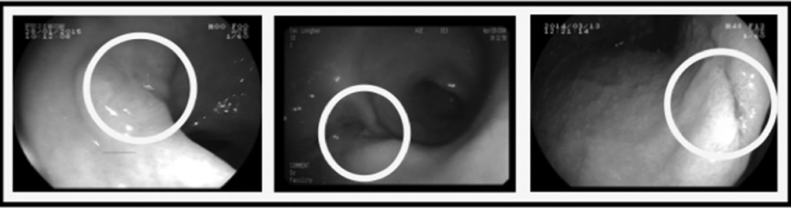

Superficial type

Abstract IDDF2019-ABS-0155 Figure1 Endoscopic features of PGI-DLBCL 